\title{
Cellular Proteases as Cancer Biomarkers: A Review
}

\author{
Sarah R. Röthlisberger ${ }^{1}$
}

Fabián M. Cortes ${ }^{2}$

\section{Abstract}

Over the past few decades a variety of biomolecules have been proposed as diagnostic biomarkers and predictors of severity for transmissible and nontransmissible diseases. Studies in a range of cancers have revealed many biomarkers with great potential in cancer diagnosis, in establishing tumor stage, progression, and response to therapies; such as the Kallikrein and Metalloproteinase families. Traditionally blood (serum) and tissue have been the main biological sources of biomarker discovery, but in the past decade urine has emerged as a promising source of cancer biomarkers. In this review we will focus on two large families, the Kallikrein family of serine proteases discovered in serum, and the Metalloproteinase family of zinc proteases discovered in urine, as potential cancer biomarkers.

\section{Keywords}

Cancer biomarkers, gene, kallikreins, metalloproteinases, protein.

1 Centro de Investigación, INSTITUTO TECNOLÓGICO METROPOLITANO, sarahrothlisberger@itm.edu.co

2 Facultad de Ingeniería, Programa de Ingeniería Biomédica, INSTITUTO TECNOLÓGICO METROPOLITANO, fabiancortes@itm.edu.co

Fecha de recepción: 22 de Agosto de 2010

Fecha de aceptación: 21 de Octubre de 2010 


\section{Resumen}

Durante las últimas décadas una gran variedad de biomoléculas han sido propuestas como biomarcadores de diagnóstico y de predicción de severidad de enfermedades transmisibles y no transmisibles. Estudios realizados en variedad de cánceres han revelado muchos biomarcadores, como las familias Kalikreina y Metaloproteinasas, con gran potencial en el diagnóstico de cáncer, en el establecimiento del grado de cáncer, su progresión y su respuesta a las terapias. Tradicionalmente la sangre (suero) y tejido han sido las principales fuentes biológicas para el descubrimiento de biomarcadores, pero en la última década ha surgido la orina como fuente prometedora de biomarcadores de cáncer. Esta revisión se centra en dos grandes familias, la familia Kalikreina de las serina proteasas, descubiertas en suero, y la familia Metaloproteinasas de las zinc proteasas, descubiertas en la orina; las cuales son biomarcadores potenciales contra el cáncer.

\section{Palabras clave}

Biomarcadores de cáncer, gen, kalikreinas, metaloproteinasas, proteína. 


\section{INTRODUCTION}

Biomarkers are molecules whose levels of expression or modifications in the body are indicative of a biological state. These biomarkers can be genetic, epigenetic, proteomic or glycomic, and have great potential in cancer diagnosis, in establishing tumor stage, progression, and response to therapies. Improved understanding of cancer pathogenesis and the development of advanced techniques has revealed a large number of potential tumor markers, such as the Kallikrein and Metalloproteinase families.

DNA, RNA and protein biomarkers are the most commonly studied. Traditionally, blood has been used as the primary biological sample for the discovery of biomarkers (Omenn, 2004); its biggest advantage being that it is in contact with all the cells in the body. However, using blood for proteomic analysis also has several disadvantages, such as the inevitable activation of proteases during sample collection, which generate an array of proteolytic products and thus introduce variability to the sample (Omenn et al., 2005). Additionally, blood has 20 high abundance proteins corresponding to $99 \%$ of the total protein (Veenstra et al., 2005), which mask the other less abundant proteins during proteomic analysis. Due to these issues urine has emerged as a potential source of biomarkers. The Human Proteome Organization (HUPO) announced in October 2005 the inclusion of the Human Kidney and Urine Proteome Project (http://hkupp.kir.jp/) as one of their projects sanctioned under the Disease Biomarker Initiative (DBI). In contrast to blood, urine collection is minimally invasive, sample handling is simple and it has been shown that urine samples are particularly stable (Schaub, et al., 2004; Theodorescu et al., 2006) which significantly reduces variability. The main disadvantage of urine is the variation in protein concentration due to differences in fluid intake during the day, but this is controlled through protein standardization to creatinine in the sample (Vestergaard \& Leverett, 1958).

Thus, along with blood, urine has emerged as a promising biological source not only for the discovery of biomarkers of 
diseases of the genitourinary tract (urological cancers, prostate cancer, etc.), but also of diseases affecting other organs of the body (brain tumors, breast cancer, and others). The first study on biomarkers in urine identified markers of brain tumors, breast, ovarian and bladder cancer (Moses et al., 1998). Most of these biomarkers were angiogenic factors (promote the formation of new blood vessels) belonging to the matrix metalloproteinase family (MMP).

Another protease family which is found in serum of cancer patients and widely researched is the Kallikrein family. Initially it was thought there were only 3 members in this family (Riegman et al., 1992), but from 1995 onwards extensive work by several research groups has revealed a total of 15 members in the human kallikrein gene family. In this review we will focus on these two protease families, the kallikrein family of serine proteases found in blood, and the metalloproteinase family of zinc proteases found in urine; both potential biomarkers in cancer diagnosis and progression.

\section{KALLIKREIN FAMILY: SERINE PROTEASES}

\subsection{Characteristics}

The kallikrein family is a group of proteins with enzymatic activity. Initially, only three kallikrein proteins were identified (classic hK): pancreatic-renal kallikrein (hK1) was first characterized in the 1930s, followed by prostate kallikrein (hK3) which was discovered from several independent studies in the 60s (Yousef \& Diamandis, 2001). The Kallikrein family was finally defined as such due to the subsequent characterization of a protein called human glandular kallikrein (hK2) (Enami \& Diamandis, 2008). Studies in the 90s, led to the identification of new family members, due to the high homology observed with the classical kallikreins at both the genomic and structural level (Yousef \& Diamandis, 2001). There are currently 15 proteins with serine-protease activity in this family, mentioned in Table 1. 
Table 1. Kallikrein Family Members

\begin{tabular}{|c|c|c|}
\hline Gene/Protein & Disease & References \\
\hline$K L K 1 / \mathrm{hK} 1$ & $\begin{array}{l}\text { Sepsis, pancreatic disease, } \\
\text { cancer }\end{array}$ & $\begin{array}{l}\text { Yousef \& Diamandis, } \\
2001\end{array}$ \\
\hline KLK2 / hK2 & Breast and prostate cancer & Partin et al., 1999 \\
\hline KLK3 / hK3 & Breast and prostate cancer & $\begin{array}{l}\text { Poliouras \& } \\
\text { Diamandis, } 2006\end{array}$ \\
\hline KLK 4 / hK4 & Ovarian cancer & Prezas et al., 2006 \\
\hline KLK5 / hK5 & Ovarian cancer & Dong et al., 2003 \\
\hline$K L K 6 / \mathrm{hK} 6$ & $\begin{array}{l}\text { Ovarian and breast cancer, } \\
\text { Alzheimer's disease }\end{array}$ & $\begin{array}{l}\text { Pampalakis \& } \\
\text { Sotiropoulou, } 2006\end{array}$ \\
\hline$K L K 7 / \mathrm{hK} 7$ & $\begin{array}{l}\text { Ovarian cancer, psoriasis, } \\
\text { keratinization }\end{array}$ & Dong et al., 2003 \\
\hline$K L K 8 / \mathrm{hK} 8$ & $\begin{array}{l}\text { Ovarian cancer, Kindling } \\
\text { epilepsy }\end{array}$ & Magklara et al., 2001 \\
\hline KLK9 / hK9 & Ovarian cancer & Yousef et al., 2001 \\
\hline$K L K 10 / \mathrm{hK} 10$ & Breast and prostate cancer & $\begin{array}{l}\text { Sidiropoulos et al., } \\
2005\end{array}$ \\
\hline KLK11 / hK11 & Ovarian and prostate cancer & Luo et al., 2006 \\
\hline KLK12 / hK12 & Breast cancer & Borgoño et al., 2004 \\
\hline KLK 13 / hK13 & Breast cancer & Chang et al., 2001 \\
\hline KLK14 / hK14 & Breast cancer & $\begin{array}{l}\text { Poliouras \& } \\
\text { Diamandis, } 2006\end{array}$ \\
\hline KLK15 / hK15 & Prostate cancer & Borgoño et al., 2004 \\
\hline
\end{tabular}

The $K L K$ genes are flanked by noncoding regions at both the $5^{\prime}$ and 3 ' ends (NTR5' and NTR3', Non-translated region) (Fig. 1). There can be two NTR regions at the $5^{\prime}$ end, whereas only one NTR has been characterized in the 3 ' end (Kurlender et al., 2004). These genes contain five exons (designated from 1 to 5), which are highly conserved in all 15 KLK family members (Fig. 1). A pattern 
of alternating intron regions of variable size, designated 0 , I, II and III, can be observed between exons (Yousef \& Diamandis, 2001). Generally, the initiation codon (AUG) is located 8-87 base pairs downstream of exon 1, while the stop codon is located between nucleotides 150-189 after the start of the coding segment of exon 5 (Pampalakis \& Sotiropoulou, 2007).

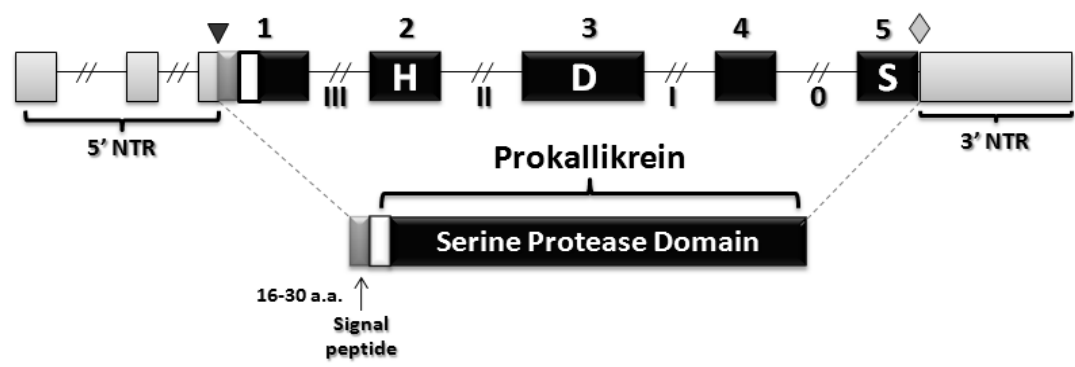

Fig. 1. Structural features of a conserved Kallikrein gene H, D and S correspond to the catalytic histidine, aspartic acid and serine residues located in the active site. Black boxes ( 1 to 5 ) indicate coding sequences. Gray boxes represent introns ( 0 to

III). Kallikrein genes are flanked by non-coding regions at 5' and 3 ' termini,

$$
\nabla \text { Start codon. } \diamond \text { Stop codon. }
$$

hK proteins synthesized from $K L K$ genes, are single-chain peptides secreted as preproenzymes. As shown in Fig. 1, each hK contains a 16-30 amino acid signal peptide in the $\mathrm{N}$-terminus, followed by a 4-9 amino acid pro-peptide and a catalytic domain that is activated by successive post-translational cleavages during its maturation stage in the secretory pathway (Yousef \& Diamandis, 2001). Generally, mature and catalytically active hK proteins are 227-252 amino acids long with approximately 10 to 12 cysteine residues which are important in the formation of disulfide bonds, and consequently for the tertiary structure; and have a highly conserved catalytic triad containing histidine $(\mathrm{H})$, aspartic acid (D) and serine (S) residues (Gomis-Ruth et al., 2002).

\subsection{Utility of Kallikreins in Biomedical Research}

Biochemical studies have determined that kallikreins are differentially expressed in human tissues, fluids and organs, 
enabling their use as biomarkers (Yousef \& Diamandis, 2001). Differential transcription of messenger RNA (mRNA) and/or protein expression has been observed in: central nervous system, thyroid, prostate, seminal fluid, testis, ovary, uterus, colon, skin, heart, breast, lung and trachea (Shaw \& Diamandis, 2007), and changes in these kallikreins have been described in several pathological processes such as inflammation, hypertension, kidney disease, pancreatitis and cancer, among others (Table 1).

\subsubsection{Prostate cancer biomarkers}

Prostate cancer is the second most common cancer in Colombian men, with an estimated annual mortality rate of 2.885 men (According to the GLOBOCAN 2002 database). Currently, diagnosis is based on serum measurements of prostate specific antigen (PSA, hK3), and a digital rectal examination of the prostate.

hK3, more commonly known as PSA, functions normally within the prostate to liquefy seminal coagulum, however it tends to be upregulated in prostate cancer. Although hK3 concentration is generally higher in serum of patients with prostate cancer, its expression is negatively regulated within the tumor tissue, which is associated with a more aggressive diagnosis (Magklara et al., 2000); hence hK3 has been associated with tumor suppressor activity, pro-apoptosis and negative regulation of cell growth (Diamandis, 2000). hK3 serves not only as a biomarker in cancer diagnosis, but also as a predictor of severity and progression.

Protein hK2 is similar to hK3 (PSA). According to some immunohistochemical studies, hK2 is expressed in higher levels in prostate tumor tissue than in hyperplastic prostate tissue or normal tissue, however other quantitative studies have reported a similar expression trend to hK3 (Finlay et al., 1998; Magklara et al., 2000). In addition to $K L K 2$ and $K L K 3$, other kallikrein family members, such as KLK5, 6, 10 and 13, are found to be negatively regulated at the transcriptional level in tumor tissue of patients with prostate cancer when compared with surrounding normal tissue (Hakalahti et al., 1993; Petraki et al., 2003; Sotiropoulou et al., 2003). 


\subsubsection{Endocrine cancer biomarkers}

Serine protease hK5 is secreted mainly by skin, testes, brain and mammary gland tissue and presents a high proteolytic activity (Shaw \& Diamandis, 2007). Transcription of KLK5 mRNA is positively regulated by steroid hormones; this has been verified in a human breast tumor cell line (BT-474) and has led to the exploration of mRNA over-expression in endocrine malignancies, revealing an increase of this biomarker in breast, testicular and ovarian cancers (Yousef et al., 2004).

In general, upregulation of mRNA or protein has been observed in kallikreins 4, 5, 6, 7, 8, 10, 11, 12, 13, 14 and 15, both in tissue and serum of patients with ovarian cancer (Table 1). In contrast, mRNA synthesis of kallikreins 3,10,12, 13 and 14, was found to be reduced in breast tumor tissue and cell lines derived from breast cancer (Yousef \& Diamandis 1999; 2001; Dhar et al., 2001 ); although $K L K 6$ mRNA is upregulated in primary breast cancer tissue, it is transcribed at a reduced rate in metastatic breast cancer (Anisowicz et al., 1996). In particular, transcription of KLK5 and KLK14 is decreased in breast cancer, although in some patients it is possible to detect elevated levels of proteins hK5 and hK14 in serum (Borgoño et al., 2006). This increased rate of $\mathrm{hK}$ synthesis can be explained by glandular destruction processes or angiogenesis, which are common events in the development of neuroendocrine tumors and may increase the level of $\mathrm{hK}$ proteins in the intravascular compartment.

Increased mRNA levels of KLK5, KLK10 and KLK14 have been reported in patients with testicular cancer when compared to healthy individuals (Luo et al., 2003), and transient transfection of the $K L K 10$ gene in breast cancer derived cell lines decreased the anchorage independent growth of these cells and their ability to form tumors (Roman-Gomez et al., 2004). These kinds of results have led to the conclusion that KLK10 is a tumor suppressor gene.

These kallikrein biomarkers are not only useful in cancer diagnosis, but are also serological markers of prognosis. For example, finding high mRNA or protein levels of kallikreins 4, 5, $6,7,10$ and 15 is considered a poor prognosis for the patient, given 
that studies have shown a more severe clinical outcome and lower rates of survival in these patients (Preza et al., 2006; Enami \& Diamandis 2008). By contrast, kallikreins 8, 9, 11 and 14 are markers of good prognosis; high concentrations of these markers are associated with higher rates of survival and recovery from illness (Borgoño et al., 2004).

\section{METALlOPROTEINASES: ZINC PROTEASES}

\subsection{Metalloproteinase Superfamily}

The metalloproteinase superfamily encodes a highly conserved zinc-binding motif containing three histidine residues which bind zinc in the active site. This superfamily includes matrix metalloproteinases (MMPs) and ADAMs (a disintegrin and metalloproteinase) (Stöcker et al. 1995).

The MMP family has 28 closely conserved members. Most MMPs share a common structure, composed of a pro-peptide domain, a catalytic domain, a hinge region, and a hemopexin-like domain (Fig. 2). At least 15 members are Zn-dependent; their activity relies on a $\mathrm{Zn}^{2+}$ metal ion bound within the catalytic domain in the conserved HExxHxxGxxH sequence (Fig. 2). The pro-peptide domain can bind to the $\mathrm{Zn}$ ion in the catalytic domain keeping the enzyme inactive, while the hemopexin-like domain is thought to be involved in protein-protein interactions, which helps determine substrate specificity. MMPs are synthesized as proenzymes and most are secreted before being converted to their active form; in order to be activated the pro-domain must be cleaved from the catalytic domain. A signal peptide at the $\mathrm{N}$ terminus targets these proteins for the secretory pathway and is removed prior to secretion from the cell. Although most MMPs are secreted proteins, integral membrane MMPs have also been described (MT-MMPs), anchored to the cell membrane by a transmembrane and intracytoplasmic domain (Jones et al., 2003). 
MMPs
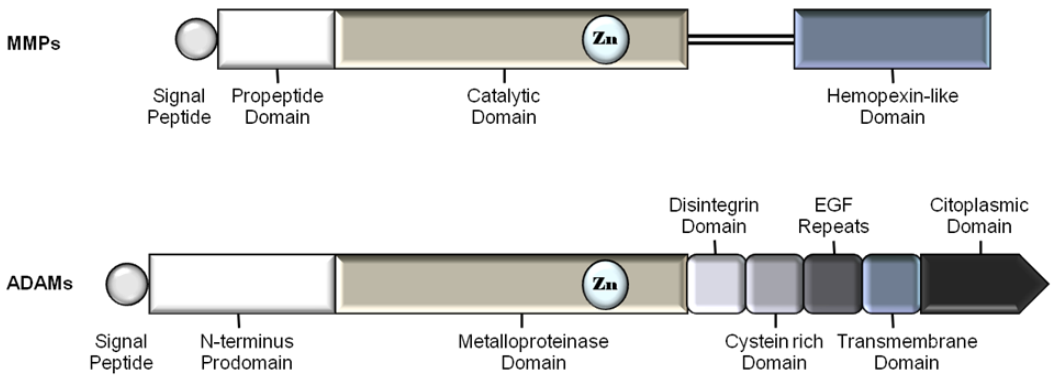

Fig. 2. Structural domains of the MMP and ADAM families. The structures shown in this figure describe the majority of MMP and ADAM family members

The main role of these human zinc proteases is in tissue remodeling. This function is exploited by tumor cells which use MMPs to break down components of the extracellular matrix, thus allowing malignant cell migration to other parts of the body (metastasis) (Fig. 3). Leukocytes that are involved in inflammatory processes are the main source of MMPs (Fig. 3).

The ADAM family (a disintegrin and metalloproteinase) is closely related to the MMP family as they are also zinc metalloproteinases and have an extracellular metalloproteinase domain (Fig. 2). ADAM proteins possess a prodomain, metalloproteinase, disintegrin, cysteine rich, EGF, transmembrane and cytoplasmic domains (Fig. 2). The metalloproteinase domain is similar to that found in MMPs and contains the same zinc-binding site. The disintegrin domain binds integrin and inhibits platelet aggregation. The cystein rich and EGF domain have many cystein residues which form disulfide bonds; however, the function of these domains is not yet well understood. Most ADAMs are integral membrane proteins, anchored with a C-terminus transmembrane domain and containing a cytosolic domain which is involved in signalling; but some members of the ADAM family are cleaved and targeted to the secretory pathway.

These proteins play a role in cell-cell and cell-matrix interactions, and in recent years evidence has emerged of ADAM proteins in tumor tissues, acting specifically in angiogenesis and metastasis processes (Lu et al., 2008) (Fig. 3). 


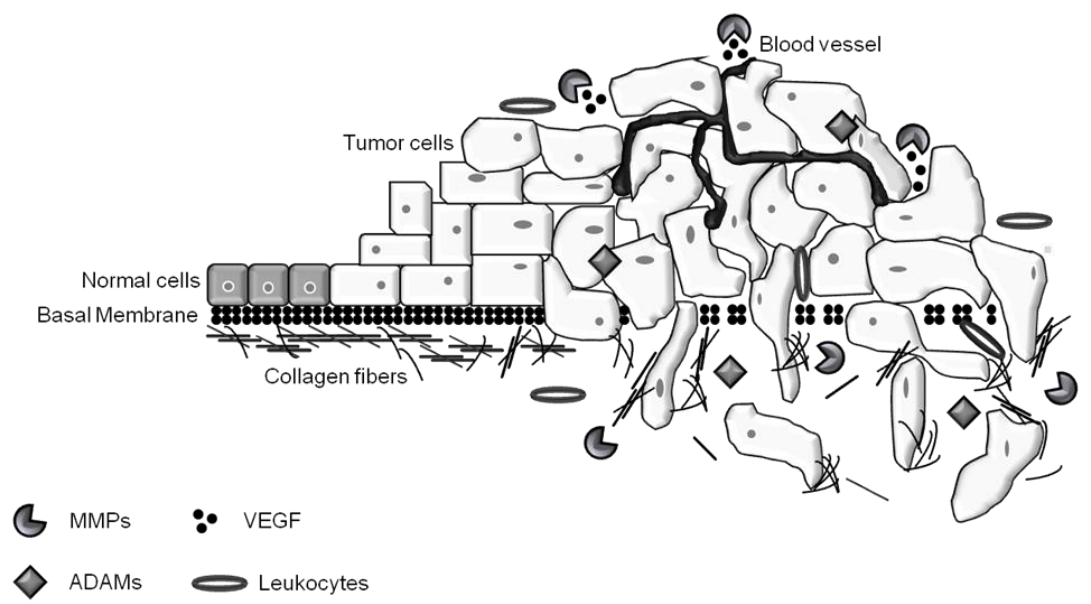

Fig. 3. Role of MMPs and ADAMs in cancer pathogenesis. MMPs and ADAMs modulate the tumor microenvironment by increasing the availability of proangiogenic factors like VEGF, thus promoting the formation of new blood vessels that feed the tumor. They also degrade the components of the basal membrane and extracellular matrix, facilitating the migration of cancer cells to other parts of the body

\subsection{Utility of MMPs in Biomedical Research}

\subsubsection{Brain tumor biomarkers}

The incidence of metastatic brain tumors is on the rise (Barker et al., 2005). The main problem in treating brain tumors is the lack of diagnostic tools to detect this disease. Two contemporary studies in 1998 addressed this issue by reporting the presence of enzymes in brain tumors (Surawicz et al., 1998) and in urine samples taken of these patients (Moses et al., 1998). Based on these publications a more detailed study was initiated in 2008 to examine the effectiveness of these proteins as potential noninvasive biomarkers of brain tumors (Smith et al., 2008).

A study with patients with a variety of brain tumors led to the discovery of metalloproteinases MMP-2, MMP-9, MMP-9/NGAL and VEGF (vascular endothelial growth factor) in urine samples collected at random, whereas these were not found in urine samples of the healthy control group (Smith et al., 2008). The 
expression patterns of these molecules found in urine reflect the expression patterns in brain tissue; patients with decreased MMP2 activity in urine also had low MMP-2 levels of expression in the tumor tissue, while patients with high MMP-9 activity in urine retained elevated levels of MMP-9 in the tumor. Additionally it was shown that elevated levels of these biomarkers in urine decreased after effective surgical treatment of the tumor. It is important to note that in serum elevated levels of MMP-9 have also been detected, in patients with colorectal cancer (Wilson et al., 2006), breast cancer (Quaranta et al., 2007) and ovarian cancer (Lin et al. , 2009).

As shown in Fig. 3, this family of metalloproteinases modulate the tumor microenvironment in several ways: a) Encouraging tumor growth by releasing insulin-like growth factor IGF. b) Promoting the formation of new blood vessels (angiogenesis) that feed the tumor, by increasing the availability of pro-angiogenic factors like VEGF. c) Facilitating the migration of cancer cells (metastasis) by degrading the extracellular matrix components. In particular two members of this family, MMP-2 and MMP-9, degrade collagen, fibronectin and laminin, which are major components of the basal membrane.

\subsubsection{Brest cancer biomarkers}

Breast cancer remains the most common cancer among women and the second leading cause of death by cancer (Parkin \& Fernandez, 2006). The priority is to identify women at high risk of developing breast cancer.

Recently, interest in a protein called ADAM-12 as a potential biomarker of breast cancer has increased. Immunohistochemical studies of breast tumor tissue have demonstrated increased expression of ADAM-12 and MMPs (Iba et al., 1999), which have also been found in high levels in the urine of these patients $(\mathrm{P}<0.001)$ (Moses et al., 1998). A well-designed study showed that women with high levels of MMP-9 and ADAM-12 in urine are 5 times more likely to develop atypical hyperplasia and 13 times more likely to develop lobular carcinoma in situ (Pories et al., 2008), which are precursors of cancer. So, these biomarkers not 
only act as indicators of the presence of breast cancer, but also as high risk predictors. It is reported that ADAM-12, expressed by cancer cells, accelerates breast cancer progression by inducing apoptosis of stromal cells (Kveiborg et al., 2005) and by degrading several extracellular matrix components such as collagen type IV and fibronectin (Roy et al., 2004).

\section{CONCLUSIONS}

The effectiveness of the Kallikrein and Metalloproteinase families as tools in cancer diagnosis, in monitoring progression, therapeutic success and recurrence of the disease, has been demonstrated. As can be seen from many of these studies, urine has emerged as an ideal non-invasive source of biomarkers; although it is a relatively recent area of work, it is one which is receiving much attention.

In the future it will be necessary to develop panels of biomarkers, given that in many cases a diseased state cannot be effectively defined using a single biomarker. For example, high levels of MMP-9 were detected in the urine of patients with brain tumors, breast and prostate cancer, among others, so MMP-9 could be used as an indicator of the existence of cancer, but would not indicate the type of cancer. A combination of general cancer biomarkers and specific biomarkers would be an optimal detection panel.

To date, of the biomarkers mentioned in this review, only hK3 (PSA) has been clinically implemented as a biomarker (of prostate cancer). Along with the discovery of new biomarkers, the challenge now will be the validation of the existent biomarkers in a large study population, and their clinical implementation.

\section{ACKNOWLEDGEMENT}

This review is a product of the prostate cancer biomarker research project; code $\mathrm{P} 10240$, funded by the INSTITUTO TECNOLÓGICO METROPOLITANO (ITM), Medellín Colombia. 


\section{REFERENCES}

Anisowicz, A., Sotiropoulou, G., Stenman, G., Mok, S.C., Sager, R. A., (1996); Novel protease homolog differentially expressed in breast and ovarian cancer. Mol Med, 2, 624-636.

Barker, F.G.II., Curry,W.T. Jr., Carter, B.S., (2005); Surgery for primary supratentorial brain tumors in the United States, 1988 to 2000: the effect of provider caseload and centralization of care. Neuro oncol, 7, 49-63.

Borgoño, C.A., Michael, I.P., Diamandis, E.P., (2004); Human tissue kallikreins: physiologic roles and applications in cancer. Mol Cancer Res, 2(5), 257-80.

Borgoño, C.A., Michael, I.P., Shaw, J.L., Luo, L.Y., Ghosh, M.C., Soosaipillai, A., Grass, L., Katsaros, D., Diamandis, E.P., (2006); Expression and functional characterization of the cancer-related serine protease, human tissue kallikrein 14. J Biol Chem, 282(4), 2405-2422.

Chang, A., Yousef, G.M., Jung, K., Meyts, E.R., \& Diamandis, E.P., (2001); Identification and molecular characterization of five novel kallikrein 13 (KLK13; KLK-L4) splice variants: differential expression in human testis and testicular cancer, Anticancer Res, 21, 3147-3152.

Dhar, S., Bhargava, R., Yunes, M., Li, B., Goyal, J., Naber, S.P., Wazer, D.E., Band, V., (2001); Analysis of normal epithelial cell specific-1 (NES1)/Kallikrein 10 mRNA expression by in situ hybridization, a novel marker for breast cancer. Clin Cancer Res, 7, 3393-3398.

Diamandis, E.P., (2000); Prostate-specific antigen: a cancer fighter and a valuable messenger?. Clin Chem, 46, 896-900.

Dong, Y., Kaushal, A., Brattsand, M., Nicklin, J., Clements, J.A., (2003); Differential splicing of KLK5 and KLK7 in epithelial ovarian cancer produces novel variants with potential as cancer biomarkers. Clin. Cancer Res, 9, 1710-1720.

Enami, N., Diamandis, E.P., (2008); Utility of Kallikrein-Related Peptidases (KLKs) as Cancer Biomarker. Clin Chem, 54, 1600-1607. 
Finlay, R., Mikolajczyk, J., Partin, S., (1998); Human kallikrein 2 (hK2) and prostate-specific antigen (PSA): two closely related, but distinct, kallikreins in the prostate. Crit. Rev. Clin. Lab. Sci, 35, 275-368.

Gomis-Ruth, F., Bayés, A., Sotiropoulou, G., Pampalakis, G., Tsetsenis, T., Villegas, V., Avilés, F., Coll, M., (2002); The Structure of Human Prokallikrein 6 Reveals a Novel Activation Mechanism for the Kallikrein Family. J Bio Chemistry, 277, 27273-27281.

Hakalahti, L., Vihko, P., Henttu, P., Autio-Harmainen, H., Soini, Y., Vihko, R., (1993); Evaluation of PAP and PSA gene expression in prostatic hyperplasia and prostatic carcinoma using northern-blot analyses, in situ hybridization and immunohistochemical stainings with monoclonal and bispecific antibodies. Int J Cancer, 55, 590-597.

Iba, K., Albrechtsen, R., Gilpin, B.J., Loechel, F. \& Wewer, U.M., (1999); Cysteine-rich domain of human ADAM 12 (meltrin alpha) supports tumor cell adhesion. Am J Pathol, 154(5), 14891-501.

Jones, C.B., Sane, D.C., Herrington, D.M., (2003); Matrix metalloproteinases: a review of their structure and role in acute coronary syndrome. Cardiovasc Res, 59(4), 812-823.

Kurlender, L., Borgoño, C., Michael, I.P., Obiezu, C., Elliott, M.B., Yousef, G.M., Diamandis, E.P., (2004); A survey of alternative transcripts of human tissue kallikrein genes, Biochim. Biophys. Acta, 1755, 1-14.

Kveiborg, M., Frohlich, C., Albrechtsen, R., Tischler, V., Dietrich, N., Holck, P., Kronqvist, P., Rank, F., Mercurio, A.M., Wewer, U.M., (2005); A role for ADAM12 in breast tumor progression and stromal cell apoptosis. Cancer Res, 65, 4754-61

Lin, B., White, J.T., Wu, J., Lele, S., Old, L.J., Hood, L., Odunsi, K., (2009); Deep depletion of abundant serum proteins reveals lowabundant proteins as potential biomarkers for human ovarian cancer. Proteomics Clin Appl, 3(7), 853-861.

Lu, X., Lu, D., Scully, M., Kakkar, V., (2008); ADAM proteins therapeutic potential in cancer. Curr Cancer Drug Targets, 8(8), 720732 .

Luo, L.Y., Shan, S.J., Elliott, M.B., Soosaipillai, A., Diamandis, E.P., (2006); Purification and characterization of human kallikrein 11, a candidate prostate and ovarian cancer biomarker, from seminal plasma. Clin Cancer Res, 12, 742-750. 
Luo, L.Y., Yousef, G., Diamandis, E.P., (2003); Human tissue kallikreins and testicular cancer. APMIS, 111, 225-232

Magklara, A., Scorilas, A., Katsaros, D., Massobrio, M., Yousef, G.M., Fracchioli, S., Danese, S., Diamandis, E.P., (2001); The human KLK8 (neuropsin/ovasin) gene: identification of two novel splice variants and its prognostic value in ovarian cancer. Clin. Cancer Res, 7, 806811.

Magklara, A., Scorilas, A., Stephan, C., Kristiansen, G.O., Hauptmann, S., Jung, K., Diamandis, E.P., (2000); Decreased concentrations of prostate-specific antigen and human glandular kallikrein 2 in malignant vs. nonmalignant prostatic tissue. Urology, 56, 527-532.

Moses, M.A., Wiederschain, D., Loughlin, K.R., Zurakowski, D., Lamb, C.C. Freeman, M.R., (1998); Increased incidence of matrix metalloproteinases in urine of cancer patients. Cancer Res, 58(7), 1395-1399.

Omenn, G. S., (2004). Advancement of biomarker discovery and validation through the HUPO plasma proteome project. Dis. Markers, 20, 131134 .

Omenn, G.S., et al., (2005); Overview of the HUPO Plasma Proteome Project: results from the pilot phase with 35 collaborating laboratories and multiple analytical groups, generating a core dataset of 3020 proteins and a publicly-available database. Proteomics, 5, 3226-3245.

Paliouras, M., Diamandis, E.P., (2006); The kallikrein world: an update on the human tissue kallikreins. Biol Chem, 387, 643-652.

Pampalakis, G., Sotiropoulou, G., (2006); Multiple mechanisms underlie the aberrant expression of the human kallikrein 6 gene in breast cancer. Biol. Chem, 387, 773-782.

Pampalakis, G., Sotiropoulou, G., (2007); Tissue Kallikrein proteolytic cascade pathways in normal physiology and cancer. Bioch et Biophy Acta, 1776, 22-31.

Parkin, D.M., Fernández, L.M., (2006); Use of statistics to assess the global burden of breast cancer. Breast J, 2, Suppl 1, S70-80.

Partin, A.W., et al., (1999); Use of human glandular kallikrein 2 for the detection of prostate cancer: preliminary analysis. Urology, 54, 839845 .

Petraki, C.D., Gregorakis, A.K., Papanastasiou, P.A., Karavana, V.N., Luo, L.Y., Diamandis, E.P., (2003); Immunohistochemical localization 
of human kallikreins 6, 10 and 13 in benign and malignant prostatic tissues. Prostate Cancer Prostatic Dis, 6, 223-227.

Pories, S.E., et al., (2008); Urinary metalloproteinases: noninvasive biomarkers for breast cancer risk assessment. Cancer Epidemiol Biomarkers Prev, 17(5), 1034-1042.

Prezas, P., Arlt, M.J., Viktorov, P., Soosaipillai, A., Holzscheiter, L., Schmitt, M., Talieri, M., Diamandis, E.P., Krüger, A., Magdolen, V., (2006); Overexpression of the human tissue kallikrein genes KLK4, 5, 6 , and 7 increases the malignant phenotype of ovarian cancer cells. Biol Chem, 387, 807-811.

Quaranta, M., et al., (2007); MMP-2, MMP-9, VEGF and CA 15.3 in breast cancer. Anticancer Res, 27(5B), 3593-3600.

Riegman, P.H., Vlietstra, R.J., Suurmeijer, L., Cleutjens, C.B., Trapman, J., (1992); Characterization of the human kallikrein locus. Genomics, 14(1), 6-11.

Roman-Gomez, J., Jimenez-Velasco, A., Agirre, X., Castillejo, J.A., Barrios, M., Andreu, E.J., Prosper, F., Heiniger, A., Torres, A., (2004); The normal epithelial cell-specific 1 (NES1) gene, a candidate tumor suppressor gene on chromosome 19q13.3-4, is downregulated by hypermethylation in acute lymphoblastic leukemia. Leukemia, 18, 362-365.

Roy, R., Wewer, U.M., Zurakowski, D., Pories, S.E., Moses, M.A., (2004); ADAM 12 cleaves extracellular matrix proteins and correlates with cancer status and stage. J Biol Chem, 279, 51323-51330.

Schaub, S., Wilkins, J., Weiler, T., Sangster, K., Rush, D., Nickerson, P., (2004); Urine protein profiling with surface-enhanced laser desorption ionization time-of-flight mass spectrometry. Kidney Int, 65, 323-332.

Shaw, J.L., Diamandis, E.P., (2007); Distribution of 15 human kallikreins in tissues and biological fluids. Clin Chem, 53(8), 1423-1432.

Sidiropoulos, M., Pampalakis, G., Sotiropoulou, G., Katsaros, D., Diamandis, E.P., (2005); Downregulation of human kallikrein 10 (KLK10/NES1) by CpG island hypermethylation in breast, ovarian and prostate cancers. Tumor Biol, 26, 324-336.

Smith, E.R., Zurakowski, D., Saad, A., Scott, R.M., Moses, M.A., (2008); Urinary biomarkers predict brain tumor presence and response to therapy. Clin Cancer Res, 14(8), 2378-2386. 
Sotiropoulou, G., Rogakos, V., Tsetsenis, T., Pampalakis, G., Zafiropoulos, N., Simillides, G., Yiotakis, A., Diamandis, E.P., (2003); Emerging interest in the kallikrein gene family for understanding and diagnosing cancer. Oncol Res, 13, 381-391.

Stöcker, W., Bode, W., (1995); Structural features of a superfamily of zincendopeptidases: the metzincins. Curr Opin Struct Biol, 5(3), 383-390.

Surawicz, T.S., Davis, F., Freels, S., Laws, E.R.Jr., Menck, H.R., (1998); Brain tumor survival: results from the National Cancer Data Base. JNeurooncol, 40, 151-160.

Theodorescu, D., Wittke, S., Ross, M.M., Walden, M., Conaway, M., Just, I., Mischak, H., Frierson, H.F., (2006); Discovery and validation of new protein biomarkers for urothelial cancer: a prospective analysis. Lancet Oncology, 7(3), 230-240.

Veenstra, T.D., Conrads, T.P., Hood, B.L., Avellino, A.M., Ellenbogen, R.G., Morrison, R.S., (2005); Biomarkers: mining the biofluid proteome. Mol Cell Proteomics, 4, 409-418.

Vestergaard, P., Leverett, R., (1958); Constancy of urinary creatinine excretion. J Lab Clin Med, 51, 211-218.

Wilson, S., Wakelam, M.J., Hobbs, R.F., Ryan, A.V., Dunn, J.A., Redman, V.D., Patrick, F., Colbourne, L., Martin, A., Ismail, T., (2006); Evaluation of the accuracy of serum MMP-9 as a test for colorectal cancer in a primary care population. BMC Cancer, 6, 258.

Yousef, G.M., Diamandis, E.P., (1999); The new kallikrein-like gene, KLK-L2. Molecular characterization, mapping, tissue expression, and hormonal regulation. J Biol Chem, 274, 37511-37516.

Yousef, G.M., Diamandis, E.P., (2001); The new human tissue kallikrein gene family: structure, function and association to disease. Endo Rev, $22,184-204$.

Yousef, G.M., et al., (2001); Quantitative expression of the human kallikrein gene 9 (KLK9) in ovarian cancer: a new independent and favorable prognostic marker. Cancer Res, 61 (21), 7811-7818.

Yousef, G.M., White, N.M., Kurlender, L., Michael, I., Memari, N., Robb, J.D., Katsaros, D., Stephan, C., Jung, K., Diamandis, E.P., (2004); The kallikrein gene 5 splice variant 2 is a new biomarker for breast and ovarian cancer. Tumour Biol, 25 (5-6), 221-227. 